\title{
Determinants of delay in malaria treatment- seeking behaviour for under-five children in south-west Ethiopia: a case control study
}

\author{
Alemayehu Getahun ${ }^{1}$, Kebede Deribe ${ }^{2}$, Amare Deribew ${ }^{3^{*}}$
}

\begin{abstract}
Background: Prompt diagnosis and timely treatment of malaria within 24 hours after onset of first symptoms can reduce illness progression to severe stages and therefore, decrease mortality. The reason why mothers/caretakers delay in malaria diagnosis and treatment for under-five children is not well studied in Ethiopia. The objective of this study was to assess determinants of malaria treatment delay in under-five children in three districts of southwest Ethiopia.

Methods: A case control study was conducted from March 15 to April 20, 2010. Cases were under-five children who had clinical malaria and sought treatment after 24 hours of developing sign and symptom, and controls were under-five children who had clinical malaria and sought treatment within 24 hours of developing sign and symptom of malaria. Data were collected by trained enumerators using structured questionnaire. Data were entered in to Epi Info version 6.04 and analyzed using SPSS version 16.0. To identify determinants, multiple logistic regression was done.
\end{abstract}

Results: A total of 155 mothers of cases and 155 mothers of controls were interviewed. Mothers of children who were in a monogamous marriage $(\mathrm{OR}=3.41,95 \% \mathrm{Cl}: 1.39,8.34)$, who complained about the side effects of antimalarial drugs ( $\mathrm{OR}=4.96,95 \% \mathrm{Cl}: 1.21,20.36)$, who had no history of child death $(\mathrm{OR}=3.50,95 \% \mathrm{Cl}: 1.82,6.42)$ and who complained about the higher cost of transportation to reach the health institutions $(\mathrm{OR}=2.01,95 \% \mathrm{Cl}$ : $1.17,3.45)$ were more likely to be late for the treatment of malaria in under-five children.

Conclusion: Effective malaria control programmes should address reducing delayed presentation of children for treatment. Efforts to reduce delay should address transport cost, decentralization of services and increasing awareness of the community on early diagnosis and treatment.

\section{Background}

By the mid-20th century, malaria was eliminated as a major health problem in many part of the world. In many parts of sub-Saharan Africa, it is still the largest contributor to the burden of disease and premature death [1-3].

During the past decades, numerous large-scale initiatives have been undertaken with the goal of reducing or eradicating the burden of malaria in the developing world. However, the ambitious goals set by these programmes for reducing the burden of malaria in the near

\footnotetext{
*Correspondence: amare_deribew@yahoo.com

${ }^{3}$ Department of Epidemiology, Director of publication and Extension, Jimma University, Jimma, Ethiopia

Full list of author information is available at the end of the article
}

future appear unlikely to be met [4]. Mortality from malaria is the major burden in under-five children. Most deaths occur at the community level, outside the health institution. Effective treatment exists, but it must be administered promptly and timely by trained personnel in order to be effective $[5,6]$.

In Africa, an estimated 300-500 million cases of malaria occur each year resulting in approximately one million deaths. Among death due to malaria occurring in Africa more than $90 \%$ are in under-five children that results in brain damage [7-9]. However, it is generally accepted that most malaria deaths can be prevented when clinical cases are promptly diagnosed and effectively treated. Major factors affecting the outcome of the diseases are health-seeking behaviour and

\section{() Biomed Central}


socio-economic status, which determine access to health services [2].

In young children, malaria can progress from a mild to severe case within 24 hours after the onset of symptoms. Prompt diagnosis and timely malaria treatment within 24 hours after onset of first symptoms can reduce illness progression to severe stages and, therefore, decrease mortality $[10,11]$. In Ethiopia, acute febrile illnesses are the leading causes of morbidity and mortality among under-five children [12-14]. Over five million episodes of malaria are estimated to occur annually and it is the top leading cause of outpatient visit and inpatient mortality $[15,16]$.

The Ethiopian malaria control and prevention strategy gives due emphasis for early diagnosis and prompt treatment [17]. However, children with malaria often times seek treatment in the late stage of the disease. Information concerning determinants of malaria treatment delay in under-five children is insufficient in Ethiopia. Therefore, this study could contribute to understanding determinants of malaria treatment delay for under-five children in local context, which is essential for malaria control in children.

Malaria is a major public health problem in Ethiopia; it contributes up to $20 \%$ of under-five deaths. Tragically, in epidemic years, mortality rates of nearly 100,000 children are not uncommon. In the last major malaria epidemic in 2003, there were up to 16 million Malaria is a major public health problem in Ethiopia; it contributes up to $20 \%$ of under-five deaths. Tragically, in epidemic years, mortality rates of nearly 100,000 children are not uncommon. In the last major malaria epidemic in 2003, there were up to 16 million.

\section{Methods}

\section{Study area and period}

A case control study was conducted from March 15 to April 20, 2010 in six health centres (Nada, Asandabo, Dimtu, Akko, Sokoru and Deneba Health centres) located in Omo Nada, Tiro Afeta and Sokoru Districts in south-west Ethiopia. The three Districts were selected purposively based on their malaria endemicity and all health centres in selected Districts were included. The study health centres are found around the Gilgel Gibe Hydroelectric dam where malaria is known to be ende$\operatorname{mic}[18,19]$.

\section{Study population}

The study population consisted of cases and controls. Cases were under-five children who had one or more signs/symptoms of malaria and positive for plasmodium species based on blood film examination and sought treatment in the health centres after 24 hours of developing sign and symptoms. Controls were under-five children who had one or more signs/symptoms of malaria and positive for Plasmodium species based on blood film examination and sought treatment within 24 hours of developing sign and symptoms at the health centres.

\section{Sample size and sampling procedure}

The sample size was calculated using Epi-Info version 6.04 statistical software. The sample size was calculated by taking distance from health institutions as a main exposure variable. From literature, it was found that proportion of individuals travelling a distance of three kilometres or more to reach the nearby health centre among controls was $27.65 \%$ [20]. By considering $80 \%$ power, Odds ratio of 2.0 , and case to control ratio of $1: 1$, the total sample size was 310 children (155 cases and 155 controls).

The survey was conducted in under-five clinics to identify and register cases and controls. Cases and controls who had malaria in the health centres were included after blood film examination. Children who had fever and negative for Plasmodium falciparum were excluded. Children visiting the health centres during the study period and fulfilling inclusion criteria were recruited till the sample size was achieved. For a case found during data collection, a consecutive control was recruited from the same health centre.

The study excluded private facilities since majorities of the private health facilities did not have laboratory facilities and treat malaria empirically based on signs and symptoms.

\section{Data collection method and tools}

Cases and controls were interviewed by trained grade 10 completed students using pre-tested and structured questionnaire. The survey tool was initially prepared in English, and translated to Afan Oromo (local language), and checked for its consistency through back translation to English by three different individuals who were health professionals. The questionnaire had two parts. The first part (socio-demographic section) encompasses age, sex, occupation, educational status, income, ethnicity, marital status, family size and communication materials. In the second part, behavioural factors, such as perception and knowledge of mothers, and health system and infrastructure-related factors were assessed.

To assess the knowledge of the respondents, 10 questions related to the signs and symptoms, mode of transmission, prevention and treatment of malaria were asked. For each question, a correct answer was given a score 1 and an incorrect answer a score 0 . A total knowledge score was constructed by summing all the scores of the knowledge questions. Individuals who scored above the mean were categorized as knowledgeable. Diagnosis of malaria was made by thick and thin blood films prepared from a finger prick and stained with Giemsa in health 
centres. Each slide was read by experienced laboratory technicians. Absence of malaria parasite in 200 high power ocular fields of the thick film was considered as negative [11].

\section{Data analysis}

Data were first checked manually for completeness and then entered into Epi-Info version 6.04. After data entry and cleaning, the data was transferred to SPSS version 16.0 for analysis. Bivariate analysis between dependent and independent variables was performed using binary logistic regression. To control the effect of confounding variables, multivariate logistic regressions were done. Variables which showed significant association in the bivariate analyses $(P<0.05)$ were candidates for the multivariate stepwise logistic regression model. Variables which were not statistically significant in the bivariate analysis were excluded in the multiple logistic regression model since they have small measure of effect (Odds ratio) and we assume such variables will not be important confounders. Adjusted OR and 95\% CI were used to interpret the findings.

The study has got ethical clearance from the Ethical Review Committee of Jimma University. The purpose of the study was explained to the study participants and written consent was obtained. Children with malaria were treated with anti-malaria drugs based on the national guideline.

\section{Results}

Socio-demographic characteristics

A total of 155 mothers of cases and 155 mothers of controls were included. The mean age of the children was $30.9(\mathrm{SD} \pm 16.51)$ months and males accounted for $188(60.7 \%)$ of the total study children. A total of 141 (91.0\%) mothers of cases and 123 (79.4\%) mothers of controls were Oromo in ethnicity, 10 (6.5\%) mothers of cases and 21 (13.5\%) mothers of controls were Amhara (Table 1).

The study tried to assess the place where treatment was sought for malaria in under-five children. A total of 152 (98.1\%) mothers/caretakers of cases and controls preferred health centres for under-five malaria treatment while 59 (38.1\%) caretakers of the cases and 43 (27.7\%) caretakers of controls preferred both health centre and health posts for the treatment of under-five malaria. The result obtained from qualitative data also showed participants preferred to visit the public health institution (Health centre, health posts) and sometimes private clinics.

\section{Determinants of delayed presentation}

In the multivariable logistic regression analysis, five variables were independently-associated with delayed malaria treatment in under-five children. Mothers in
Table 1 Socio-demographic characteristics of respondents in Omo Nada, Tiro Afeta and Sokoru Districts, southwest Ethiopia, April, 2010

\begin{tabular}{|c|c|c|}
\hline \multirow[t]{2}{*}{ Variable } & \multicolumn{2}{|c|}{ Patient Category } \\
\hline & Cases & Controls \\
\hline \multicolumn{3}{|c|}{ Age category of the respondent } \\
\hline $15-25$ & 49 (31.6\%) & $60(38.7 \%)$ \\
\hline $26-35$ & $94(60.6 \%)$ & $84(54.2 \%)$ \\
\hline$\geq 36$ & $12(7.7 \%)$ & $11(7.1 \%)$ \\
\hline \multicolumn{3}{|c|}{ Occupation of the respondent } \\
\hline Farmer & $76(49.0 \%)$ & $66(42.6 \%)$ \\
\hline Gov't employee & $17(11.0 \%)$ & $20(12.9 \%)$ \\
\hline NGO employee & $1(0.6 \%)$ & $4(2.6 \%)$ \\
\hline Student & $8(5.2 \%)$ & $9(5.8 \%)$ \\
\hline House wife & $49(31.6 \%)$ & $40(25.8 \%)$ \\
\hline Merchant & $4(2.6 \%)$ & $16(10.3 \%)$ \\
\hline \multicolumn{3}{|c|}{ Average monthly income } \\
\hline$\leq 500.00$ & $7(4.5 \%)$ & $12(7.7 \%)$ \\
\hline $501.00-999.00$ & $67(43.2 \%)$ & $50(32.3 \%)$ \\
\hline$\geq 1000$ & $81(52.3 \%)$ & $93(60.0 \%)$ \\
\hline \multicolumn{3}{|c|}{ Educational status of the respondent } \\
\hline Illiterate & $77(49.7 \%)$ & $59(38.1 \%)$ \\
\hline Read and write & $25(16.1 \%)$ & $25(16.1 \%)$ \\
\hline 1 - 4 grade & $8(5.2 \%)$ & $14(9.0 \%)$ \\
\hline 5 - 8 grade & $21(13.5 \%)$ & $24(15.5 \%)$ \\
\hline 9 - 10 grade & $13(8.4 \%)$ & $19(12.3 \%)$ \\
\hline preparatory \& + & $11(7.1 \%)$ & $14(9.0 \%)$ \\
\hline \multicolumn{3}{|c|}{ Family size of the household } \\
\hline$\leq 3$ & $11(7.1 \%)$ & $23(14.8 \%)$ \\
\hline $4-6$ & $97(62.6 \%)$ & $96(61.9 \%)$ \\
\hline$>6$ & $47(30.3 \%)$ & $36(23.2 \%)$ \\
\hline \multicolumn{3}{|l|}{ Type of marriage } \\
\hline Polygamy & $44(35.2 \%)$ & $9(6.7 \%)$ \\
\hline Monogamy & $81(64.8 \%)$ & $126(93.3 \%)$ \\
\hline \multicolumn{3}{|c|}{ Number of under-five children in the house hold } \\
\hline $1-2$ & $130(83.9 \%)$ & $136(87.7 \%)$ \\
\hline $3-4$ & $25(16.1 \%)$ & $19(12.3 \%)$ \\
\hline \multicolumn{3}{|c|}{ Age category of the child (in month) } \\
\hline$\leq 12$ & $37(23.8 \%)$ & $34(21.9 \%)$ \\
\hline $13-24$ & $39(25.2 \%)$ & $36(23.2 \%)$ \\
\hline$>24$ & $79(50.8 \%)$ & $85(54.8 \%)$ \\
\hline \multicolumn{3}{|l|}{ Sex of the child } \\
\hline Male & $91(58.7 \%)$ & $97(62.6 \%)$ \\
\hline Female & $64(41.3 \%)$ & $58(37.4 \%)$ \\
\hline
\end{tabular}

monogamous marriage were more likely to seek treatment for under-five children late than mothers in polygamous marriage $(\mathrm{OR}=3.41 ; 95 \% \mathrm{CI}: 1.39-8.34)$. Mothers who had no history of child death were more likely to bring their under-five children late for the treatment of malaria than mothers who had history of child death $(\mathrm{OR}=3.50,95 \% \mathrm{CI}: 1.88,6.42)$. Mothers who complained about the side effects of anti-malarial 
drugs were more likely to have delayed under-five children for malaria treatment than mothers who did not complain about the side effects of the drugs $(\mathrm{OR}=4.96$, 95\% CI: 1.21-20.36). As the cost of transportation increase, the pattern of delay increases. Mothers who lived in a village more than three kilometres from a health centre were more likely to be late for the treatment of malaria for under-five children than mothers who live less than three kilometres from the health institutions $(\mathrm{OR}=2.01,95 \% \mathrm{CI}$ : 1.17-3.45) (Table 2).

\section{Discussion}

This study explored factors associated with delayed malaria treatment in under-five children for the first time in Ethiopia. Marital status, distances from the health institutions, and perceived side effects of the drugs were the major factors associated with delay in malaria treatment in under-five children. Occupational status of the household heads and mothers of under-five children was not associated with delay in malaria treatment for under-five children, which is in contrast with the study done in Tanzania where being a farmer was associated with delay in malaria treatment $[3,6]$. Similarly, educational status of mothers did not show an association with delay in diagnosis and treatment of malaria in under-five children. However, a study done in Burkina Faso showed that literacy level of the heads of the households was the main factor to bring children within 24 hours to the health facility for the treatment of malaria [21].
In this study, age and sex of the child were not associated with delay in malaria diagnosis and treatment for under-five children. Similar findings were documented elsewhere [3,6,21]. However, a study done in Nairobi slum areas showed that boys were more likely to get early diagnosis and treatment of malaria than girls [22].

Children who had monogamous parents were three times more likely to have delay in diagnosis and treatment of malaria when compared to children who had polygamous parents (OR, 3.41; 95\% CI, 1.39, 8.34). Husbands in polygamous marriage may be overwhelmed by more farming activities for the livelihoods of their family. In such circumstances, decisions on health-seeking behaviour of children may be in the hands of wives who are more responsible than males for their children to seek early care. Where as in monogamous marriage, males are responsible for every decision in the household and they may be more reluctant than females to take their children to the health facility early. On the other hand, wives in polygamous marriage could compete each other to make their children healthy and alive so as to get a blessing from their husband. Polygamous family may also have good income to take sick children early to the health institution than monogamous family.

The majority of respondents have knowledge on sign and symptom of malaria as well as its prevention and control methods. However, knowledge of respondents is not associated with delay in malaria treatment. Similar studies elsewhere also showed that that knowledge on malaria

Table 2 Variables associated with delay in malaria treatment-seeking behaviour for under-five children in southwest Ethiopia, April, 2010

\begin{tabular}{|c|c|c|c|c|}
\hline \multirow[t]{2}{*}{ Variables } & \multicolumn{2}{|c|}{ Patient category } & \multirow{2}{*}{$\begin{array}{r}\text { Crude } \\
\text { OR(95\% Cl) }\end{array}$} & \multirow{2}{*}{$\begin{array}{r}\text { Adjusted } \\
\text { OR(95\% Cl) }\end{array}$} \\
\hline & Case & Control & & \\
\hline \multicolumn{5}{|l|}{ Type of marriage } \\
\hline Monogamy & $44(35.2 \%)$ & $9(6.7 \%)$ & $3.99(2.08,7.65)$ & $3.41(1.39,8.34)^{*}$ \\
\hline Polygamy & $81(64.8 \%)$ & $126(93.3 \%)$ & 1.00 & 1.00 \\
\hline \multicolumn{5}{|c|}{ History of child death } \\
\hline Yes & $17(11.0 \%)$ & $47(30.3 \%)$ & 1.00 & 1.00 \\
\hline No & $138(89.0 \%)$ & $108(69.7 \%)$ & $3.53(1.92,6.50)$ & $3.50(1.88,6.42)^{*}$ \\
\hline \multicolumn{5}{|c|}{ Presence of side effects } \\
\hline Yes & $40(25.8 \%)$ & $4(2.6 \%)$ & $13.13(4.56,37.75)$ & $4.96(1.21,20.36)^{*}$ \\
\hline No & $115(74.2 \%)$ & 151(97.4\%) & 1.00 & 1.00 \\
\hline \multicolumn{5}{|c|}{ Cost of transportation } \\
\hline Expensive & $31(20.0 \%)$ & $6(3.9 \%)$ & $12.50(4.74,32.94)$ & $4.94(1.20,20.26)^{*}$ \\
\hline Optimum & $58(37.4 \%)$ & $48(31.0 \%)$ & $2.92(1.65,5.15)$ & $2.26(1.11,4.61)^{*}$ \\
\hline Cheap & $35(22.6 \%)$ & $26(16.8 \%)$ & $3.25(1.68,6.28)$ & $2.69(1.23,5.91)^{*}$ \\
\hline No fee & $31(20.0 \%)$ & $35(48.4 \%)$ & 1.00 & 1.00 \\
\hline \multicolumn{5}{|c|}{ Distance of health institution (m) } \\
\hline$\leq 3000$ & $59(38.1 \%)$ & $100(64.5 \%)$ & 1.00 & 1.00 \\
\hline$>3000$ & $96(61.9 \%)$ & $55(35.5 \%)$ & $2.96(1.86,4.70)$ & $2.01(1.17,3.45)^{*}$ \\
\hline
\end{tabular}

*P value less than 0.05 . 
transmission was not associated with timely treatment seeking behaviour for under-five children [23,24]. Knowledge about the role of mosquitoes on the transmission of malaria was not also associated with timely and appropriate help seeking behaviour for children even though such knowledge may promote personal protective measures, especially use of bed nets $[23,24]$.

Mothers who complained about the side effect of drugs prescribed by health personnel before the illness of the current child were more likely to have delay in malaria treatment for under-five children. Due to lack of proper counselling and education, mothers may perceive that the side effects of anti-malaria drugs are very harmful than their benefits.

Mothers living within three-kilometre radius of health institution tend to seek malaria treatment for under-five children earlier. This finding supports the result of the study done in Uganda and Ethiopia which showed that mothers travelling a distance of less than three kilometres seek treatment for under-five malaria earlier than those who travel greater or equal to three kilometres $[19,25]$. This could be due to the location advantage of those who are nearer to the facility. In addition, the result indicated that cost incurred for transportations results in delay in malaria diagnosis and treatment.

Mothers who have history of under-five deaths tend to seek treatment earlier. This implies that perceived risk and severity of the illness affects treatment-seeking behaviours. Lack of quality control of the laboratory investigation of malaria was the major limitation of this study. As a result, there might be misclassification of cases and controls. Severity signs and symptoms of malaria among the study children were not assessed. Treatment seeking behaviour might have been affected by the severity signs of malaria.

\section{Conclusion}

Complaint about the side effects of anti-malarial drugs, distant and cost of transportation to reach the health facilities, monogamous marriage and absence of underfive death which is a proxy measure of perceived severity of malaria were associated with delay in diagnosis and treatment of malaria. The malaria control programme should focus on increasing access to malaria treatment at the lowest facilities; address transport cost, increasing awareness of the community on early diagnosis and treatment and addressing patients concerns about the side effects of anti-malarial drugs.

\section{Acknowledgements}

This investigation received financial support from Jimma University. The authors appreciate the study participants for their cooperation in providing the necessary information. We acknowledge the local administrators and the community for their strong support during the survey.

\section{Author details}

${ }^{1}$ Wollega University, Nakamte, Ethiopia. ${ }^{2}$ Fayya Development Association, Addis Ababa, Ethiopia. ${ }^{3}$ Department of Epidemiology, Director of publication and Extension, Jimma University, Jimma, Ethiopia.

\section{Authors' contributions}

AG conceived the study and was involved in the analysis and Report writing. KK was involved in data analysis and review. AD was involved in the conception, design, and data analysis and drafted the manuscript. All authors read and approved the manuscript.

\section{Competing interests}

The authors declare that they have no competing interests.

Received: 13 September 2010 Accepted: 11 November 2010 Published: 11 November 2010

\section{References}

1. Arrow K, Panosian CB, Gelband $H$, (eds): Saving lives, buying time: economics of malaria drugs in the age of resistance. Washington DC: The National Academies Press; 2004.

2. WHO: Fighting disease, Fostering development. The World Health Report 1996 Geneva: World Health Organization; 1996.

3. Dillip A, Hetzel MW, Gosoniu D, Kessy F, Lengeler C, Mayumana I, Mshana C, Mshinda H, Schulze A, Makemba A, Pfeiffer C, Weiss MG, Obrist B: Socio-cultural factors explaining timely and appropriate use of health facilities for degedege in south-eastern Tanzania. Malar J 2009, 8:144.

4. Attaran A, Barnes K, Curtis C: WHO, the Global Fund, and medical malpractice in malaria treatment. Lancet 2004, 363:237-240.

5. Snow R, Craig M, Deichmann U, Marsh K: Estimating mortality, morbidity and disability due to malaria among Africas non-pregnant population. Bull World Health Organ 1999, 77:624-640.

6. Savigny D, Mayombana C, Mwageni E, Masanja H, Minhaj A, Mkilindi Y, Mbuya C, Kasale H, Reid G: Care-seeking patterns for fatal malaria in Tanzania. Malar J 2004, 3:27.

7. Maslove DM, Mnyusiwalla A, Mills EJ, McGowan J, Attaran A, Wilson K: Barriers to the effective treatment and prevention of malaria in Africa: A systematic review of qualitative studies. BMC Int Health Hum Rights 2009, 9:26.

8. Centers for Disease Control and Prevention: Global Malaria Prevention and Control Program: Moving Ahead in the 21st Century. Centers for Disease Control and Prevention, Atlanta, USA 2001.

9. World Health Organisation: Hide copyright information)Clinical, Behavioural and Socioeconomic Factors Related to Severe Malaria: A Multicentre Study in the African region. World Health Organization, Regional Office for Africa 2002.

10. Baird J: Effectiveness of antimalarial drugs. N Engl J Med 2005, 352:1565-1577.

11. Baume CA: Guide to research on care-seeking for childhood malaria. Arlington, Virginia: SARA, BASICS II; 2002.

12. Ministry of Health, Ethiopia: Guidelines for Malaria Epidemic Prevention and Control in Ethiopia. Disease prevention and Control Department Addis Ababa; 1999.

13. Ministry of Health, Ethiopia: Health and Health Related Indicators 2004/ 2005. Planning and Programming Department. FMOH Addis Ababa; 2005.

14. Friends of the global fund Africa: Ethiopia is turning the tide against malaria with global fund. Lagos, Nigeria 2008.

15. Ministry of Health, Ethiopia: Entomological Profile of Malaria in Ethiopia; African network on vector resistance. WHO/Regional office for Africa; 2007.

16. Ministry of Health, Ethiopia: Health and health related indicators 2003/04. Planning and Programming Department. FMOH Addis Ababa; 2004.

17. Ministry of Health, Ethiopia: Malaria Prevention and control Extension Package. MOH Addis Ababa; 2003.

18. Jimma University: Institute of Health Sciences Research: Gilgel Gibe Research Centre. Jimma University; 2006.

19. Ethiopian Light and Power Authority: Gilgel Gibe Hydroelectric Project, environmental assessment main report. Ministry of Mines and Energy Addis Ababa, Ethiopia; 1997. 
20. Ndyomugyenyi R, Magnussen P, Clarke S: Malaria treatment-seeking behavior and drug prescription practices in an area of low transmission in Uganda: implications for prevention and control. Transactions of the Royal Society of Tropical Medicine and Hygiene 2007, 101:209-215.

21. Tipke $M$, Louis RV, Yé $M$, et al: Access to malaria treatment in young children of rural Burkina Faso. Malaria Journal 2009, 8(266).

22. Taffa $\mathrm{N}$, Chepngeno G: Determinants of health care seeking for childhood illnesses in Nairobi slums. Tropical Medicine and International Health 2005, 10(3):240-245.

23. Legesse $\mathrm{M}$, Deressa $\mathrm{W}$ : Community awareness about malaria, its treatment and mosquito vector in rural highlands of central Ethiopia. Ethiop I Health Dev 2009, 23(1):40-47.

24. Ahorlu CK, Koram KA, Ahorlu C, de Savigny D, Weiss MG: Socio-cultural determinants of treatment delay for childhood malaria in southern Ghana. Trop Med Int Health 2006, 11:1022-1031.

25. Rutebemberwa E, Kallander K, Tomson G, Peterson S, Pariyo G: Determinants of delay in care-seeking for febrile children in eastern Uganda. Trop Med Int Health 2009, 14:472-479.

doi:10.1186/1475-2875-9-320

Cite this article as: Getahun et al:: Determinants of delay in malaria treatment-seeking behaviour for under-five children in south-west Ethiopia: a case control study. Malaria Journal 2010 9:320.

\section{Submit your next manuscript to BioMed Central} and take full advantage of:

- Convenient online submission

- Thorough peer review

- No space constraints or color figure charges

- Immediate publication on acceptance

- Inclusion in PubMed, CAS, Scopus and Google Scholar

- Research which is freely available for redistribution

Submit your manuscript at www.biomedcentral.com/submit 